\title{
DIAGONAL RECURRENCE RELATIONS, INEQUALITIES, AND MONOTONICITY RELATED TO THE STIRLING NUMBERS OF THE SECOND KIND
}

\author{
FENG QI
}

Abstract. In the paper, the author derives several "diagonal" recurrence relations, constructs some inequalities, finds monotonicity, and poses a conjecture related to the Stirling numbers of the second kind.

Mathematics subject classification (2010): Primary 11B73; Secondary 05A18, 11B83, 11R33, 26D15, 33B10, 44A10.

Keywords and phrases: Stirling number of the second kind, diagonal recurrence relation, inequality, logarithmically convex sequence, monotonicity, Faà di Bruno formula, Bell polynomials of the second kind, conjecture.

\section{REFERENCES}

[1] L. Comtet, Advanced Combinatorics: The Art of Finite and Infinite Expansions, Revised and Enlarged Edition, D. Reidel Publishing Co., Dordrecht and Boston, 1974.

[2] B.-N. GUO AND F. QI, An explicit formula for Bernoulli numbers in terms of Stirling numbers of the second kind, J. Anal. Number Theory 3 (2015), no. 1, 27-30; Available online at http://dx.doi.org/10.12785/jant/030105.

[3] D. S. Mitrinović AND J. E. PeČARIĆ, On two-place completely monotonic functions, Anzeiger Öster. Akad. Wiss. Math.-Natturwiss. Kl. 126 (1989), 85-88.

[4] D. S. Mitrinović, J. E. PeČARIĆ, And A. M. Fink, Classical and New Inequalities in Analysis, Kluwer Academic Publishers, 1993; Available online at http://dx.doi.org/10.1007/ 978-94-017-1043-5.

[5] J. E. PEČArIĆ, Remarks on some inequalities of A. M. Fink, J. Math. Anal. Appl. 104 (1984), no. 2, 428-431; Available online at http://dx. doi .org/10.1016/0022-247X (84) 90006-4.

[6] F. QI, A recurrence formula, some inequalities, and monotonicity related to Stirling numbers of the second kind; Available online at http://arxiv.org/abs/1402.2040.

[7] F. QI, Diagonal recurrence relations for the Stirling numbers of the first kind, Contrib. Discrete Math. 10 (2015), in press; Available online at http://arxiv.org/abs/1310.5920.

[8] F. QI, Integral representations and properties of Stirling numbers of the first kind, J. Number Theory 133 (2013), no. 7, 2307-2319; Available online at http://dx.doi.org/10.1016/j.jnt. 2012.12.015.

[9] M. SibuYa, Log-concavity of Stirling numbers and unimodality of Stirling distributions, Ann. Inst. Statist. Math. 40 (1988), no. 4, 693-714; Available online at http://dx.doi.org/10.1007/ BF00049427.

[10] Z.-Z. Zhang And J.-Z. YAnG, Notes on some identities related to the partial Bell polynomials, Tamsui Oxf. J. Inf. Math. Sci. 28 (2012), no. 1, 39-48. 